\title{
Private pension funds: passivity at active fund prices
}

\section{Carlos Heitor Campani}

Universidade Federal do Rio de Janeiro, Instituto COPPEAD de Administração, Departamento de Finanças e Controle Gerencial, Rio de Janeiro, RJ, Brazil

Email: carlos.heitor@coppead.ufrj.br

\section{Leonardo Mesquita de Brito}

Universidade Federal do Rio de Janeiro, Instituto COPPEAD de Administração, Departamento de Finanças e Controle Gerencial, Rio de Janeiro, RJ, Brazil

Email: leomesq135@gmail.com

Received on 09.09.2016 - Desk acceptance on 09.22.2016 - $3^{\text {rd }}$ version approved on 07.12.2017 - Ahead of print on 11.06.2017

\begin{abstract}
From 2005 to 2015, the total assets managed by open private pension funds increased more than six times in Brazil, where the Free Benefit Generating Plan (PGBL) and the Free Benefit Generating Life (VGBL) represent $90 \%$ of these assets. However, private pension institutions are characterized by the collection of high management fees, thus keeping for themselves much of the benefits offered by the government as incentive for investment in this modality. High management fees are justified only when there is active management of these funds, theoretically generating higher performance: this study indicates that this is not the case in this market segment. Similar problems have been faced in other countries, such as the United Kingdom, Denmark, and Sweden, which filed investigation concerning funds that charge high management fees for active management, while they actually provide management that may be regarded as passive. This demonstrates the scale and relevance of this issue, which has been surveyed and addressed by this study. To do this, dynamic style analysis was performed, through rolling regressions, followed by Kalman filter analysis in funds from the top-five private pension institutions in Brazil. Analyzing the exposure evolution of these funds to various asset classes and the $\mathrm{R}^{2}$ generated, passivity traces were found, mainly in composite variable income funds. Such funds are precisely those that should be more actively managed, as they charge the highest management fees. This article also demonstrates it is possible to build a passive portfolio, having a very similar style and returns without statistically significant differences, but at a lower management fee (and aligned with passive funds).
\end{abstract}

Keywords: private pension, investment strategy, style analysis, Kalman filter, passive funds.

Correspondence address:

Carlos Heitor Campani

Universidade Federal do Rio de Janeiro, Instituto COPPEAD de Administração

Rua Pascoal Lemme, 355 - CEP: 21941-616

Cidade Universitária - Rio de Janeiro - RJ - Brazil 


\section{INTRODUCTION}

The open private pension market has been growing consistently in Brazil for at least 10 years, at an average rate of $20 \%$ per year (p.y.), reaching the mark of $\mathrm{R} \$$ 500 billion in 2015, according to data provided by the Brazilian National Federation of Private Pension and Life (FenaPrevi). In this market, plans known as the Free Benefit Generating Plan (PGBL) and the Free Benefit Generating Life (VGBL) have become very popular and they currently account for $90 \%$ of the sector, making up almost all new products. Such private pension plans have advantages over traditional investment funds. For instance, the Brazilian income tax (IR) is deferred for redemptions only (as opposed to quota-eaters from traditional funds) and there is the possibility of using a much more generous regressive IR chart with long-term investors. Such plans are also structured as Brazilian specially constituted investment funds (FIEs); more details can be found in Campani and Costa (2016).

The focus of this article lies precisely on this class of assets that has increasingly stood out among the investment alternatives in the Brazilian market: private pension funds. More specifically, we analyze the FIEs of PGBL and VGBL private pension plans from the five largest institutions in terms of equity in Brazil. In general, private pension institutions have the characteristic of collecting high management fees in their funds. The average value for fixed income pension funds in these institutions is $2 \%$ p.y., mainly for small investors, with up to $\mathrm{R} \$ 100,000$ invested. These fees are only justified if there is active management of these funds, theoretically generating higher performance.

Broadly reported by major newspapers, such as the well-known and reputed Financial Times (reports available upon request to authors), some European countries, led by Sweden, have recently begun to investigate funds that charge high management fees for active management while they actually provide management that may be regarded as passive, replicating the performance of market indexes already known. Debate on this issue, either in the academia or in international regulatory bodies, has been growing and, according to the Financial Times, pressure on these funds, named as closet trackers, begins to gain momentum across Europe.

So, the purpose of this paper is shedding light and introduce the debate in Brazil, through dynamic style analysis based on private pension funds' return in Brazil, in order to evaluate the dynamic exposures of these funds to the main asset classes in the Brazilian market. Thus, it is possible to discuss whether private pension funds have been meeting what investors expect, either in terms of performance above a passive benchmark or in terms of fees charged in relation to the fund's activity level, or in terms of compliance with self-declared strategies (i.e. relation between variable income and fixed income in their portfolios).

The next section presents a brief theoretical framework with a literature review that supports this research. Subsequently, we introduce the methodology, as well as the data used, and then we present the results, analyses, and conclusions.

\section{THEORETICAL REFERENCE AND LITERATURE REVIEW}

\subsection{Private Pension Funds}

Private pension funds have a special tax treatment in Brazil, with peculiar advantages when compared to non-pension funds. For instance, the absence of quotaeaters, deferring the IR for redemptions only, the possible restitution of an IR portion paid at the source, and the exclusive IR chart, allowing a rate of only $10 \%$ in the long term, are benefits that make such funds highly attractive to long-term investors. Campani and Costa (2016) analyze these benefits and compare pension funds to non-pension funds, evidencing (and quantifying) the high value of these benefits. On the other hand, they emphasize that loading and management fees of pension funds are still (much) higher than those of non-pension funds, something which ultimately undermines the net profitability of such funds. This confirms the study by Amaral (2013), which concludes that non-pension funds have higher performance; in other words, a part of the tax gains does not reach the investor.

However, it is possible to perceive, in the market, an alignment tendency between the fees charged by pension funds and non-pension funds, and this difference has decreased considerably over the years. Thereby, pension 
funds have everything to gain even more recognition in the Brazilian investment scenario. According to a regulation by the Brazilian Superintendency of Private Insurance (SUSEP), a pension fund may declare itself conservative (having 100\% of its quotas invested in fixed income) or composite, investing up to $49 \%$ in variable income. Thus, all institutions that offer pension funds are conservative, moderate, and aggressive, indicating the degree of investment in variable income, from $0 \%$ (conservative) to $49 \%$ (aggressive), or less, according to their own strategy.

For this study, we selected PGBL and VGBL funds from the five main financial institutions in Brazil. Since the objective is conducting style analysis, in order to ascertain the degree of activism in each fund, funds' profitability have been recomposed to transaction costs (i.e. full). This is because the costs might generate unnecessary noise in the analysis, as the objective is finding out which asset classes and how much they contribute to funds' profitability.

\subsection{Return-Based Style Analysis}

\subsubsection{The return-based style analysis proposed by William F. Sharpe.}

According to Varga and Valli (1998), pioneers in the introduction of style analysis in Brazil, the classification of investment funds available in the market as for exposure to various asset classes - each carrying a different type of risk - is an extremely important problem for investors. They need to know the sources of risk and the resource allocation strategies to which their investment portfolios are exposed, in order to form optimal portfolios for each different profile.

To solve this problem, Sharpe $(1988,1992)$ proposed a statistical approach that compares the return series of the fund under analysis to return series of several indexes, representing the asset classes to which the fund might be exposed. The methodology proposed by Sharpe (1992), the return-based style analysis (RBSA), consists in using a model of asset class factors. The generic representation of a factor model may be:

$$
\widetilde{\mathrm{R}}_{\mathrm{i}}=\left[\mathrm{b}_{\mathrm{i} 1} \tilde{\mathrm{F}}_{1}+\mathrm{b}_{\mathrm{i} 2} \tilde{\mathrm{F}}_{2}+\cdots+\mathrm{b}_{\mathrm{in}} \tilde{\mathrm{F}}_{\mathrm{n}}\right]+\tilde{\mathrm{e}}_{\mathrm{i}}
$$

where $\widetilde{\mathrm{R}}_{1}$ represents the return of fund $i, \widetilde{\mathrm{F}}_{1}$ represents the value of factor $1, \widetilde{\mathrm{F}}_{2}$ the value of factor $2, \widetilde{\mathrm{F}}_{\mathrm{n}}$ the value of the nth (last) factor, and $\widetilde{\mathrm{e}}_{1}$ the component of return that is not explained by the factors. The $\mathrm{b}_{\mathrm{ij}}$ represents the sensitivities of $\widetilde{R}_{1}$ to the factors $\widetilde{\mathrm{F}}_{j}$. All these values are not known before the fact, so the use of tis.

Sharpe (1992) regards his methodology as an individualization of this type of generic factor model. In the model proposed by him, each factor represents an asset class' return. The sensitivities, in order to represent the weights of these classes in the portfolio, must add up to $100 \%$ and individually they must be between $0 \%$ and $100 \%$ (assuming there is no short sale). Thus, the return of a fund $i$ would be represented by the return of a portfolio inxested in $n$ asset classes - a return which is given by the sum in brackets of equation 1 plus a residual component $\left(e_{1}\right)$. He still interprets this sum in brackets as representing the fund's style, while the residual might be attributable to the specific and dynamic (i.e. active) selection of the assets.

Over time, several studies have started to use and improve the technique proposed by Sharpe $(1988,1992)$. More specifically in Brazil, we may cite some major works, such as: Amaral (2013), Linhares (2003), Marques (2006),
Nunes (2015), Varga and Valli (1998), and Yoshinaga, Castro Jr., Oda and Lucchesi (2009). Among the authors who have used variations and improvements of the RBSA in Brazil, we may mention Marques, Pizzinga and Vereda (2012), Pizzinga, Vereda, Azevedo and Fernandes (2012), and Schutt and Caldeira (2014), who used a more advanced methodology: the Kalman filter, applied to style analysis to determine how fund exposures to asset classes of vary over time. This methodology is detailed below, since it is used by this study.

\subsubsection{Return-based dynamic style analysis.}

Using the technique proposed by Sharpe $(1988,1992)$, several problems and attempts to correct them have been emerging. One of the major drawbacks of using the style analysis proposed by the author is that it implicitly assumes that the class exposure style is constant over time. Exactly for this reason, Fung and Hsieh (1997) explain that simple RBSA does not work so well when applied in active funds. The turnover of exposures to the various asset classes is high and, precisely because of this, they are able to stand out in terms of performance.

In the literature on the subject, there were several approaches to make the RBSA dynamic. One of the most 
used, and perhaps also the simplest one, takes place through the use of movable windows. A window size is arbitrated - Lhabitant (2009), for instance, proposes to divide the analysis period into two - and the analysis takes place within this period. Next, such a window is 'rolled' a time interval forward and the analysis for this period is replicated, repeating this procedure to the end. Among the authors who have used this technique in their studies there are Gibson and Gyger (2007), Holmes and Faff (2008), Linhares (2003), Marques (2006), Marques, Pizzinga and Vereda (2012), and Varga and Valli (1998).

However, Markov, Mottl and Muchnik (2004) highlight a major problem in attempting to capture the dynamics of allocation across asset classes through movable windows: the technique does not do well with structural breaks, since it over-smoothes transitions, taking a long time to fully capture them. The methodology most frequently used in the literature to deal with this problem consists in modeling it as a state space, using some method to estimate the unknown parameters, and a recursive algorithm to estimate the states. Among the options, the most frequently used and consolidated in the literature is the Kalman filter, which is the method used in this paper and, therefore, described in greater detail below.

\subsection{State Space Modeling}

State space modeling is only a convenient notation to make it easier to understand and estimate stochastic models where measurement errors are assumed in the system, thus it may be used for many time series models. Among the main works in this field, those by Durbin and Koopman (2012) and Harvey (1990), among others, stand out.

Specifically in the proposal to turn the model by Sharpe (1992) into exposures that are totally dynamic, the objective becomes determining the weights of each index that represents the asset classes in each time interval $t$. Thus, we may rewrite the model by Sharpe (1992) generically, with exposures explicitly varying in time, as follows:

$$
\begin{gathered}
\mathrm{R}_{\mathrm{t}}^{\mathrm{fu}}=\alpha_{\mathrm{t}}+\beta_{1, \mathrm{t}} \cdot \mathrm{R}_{1, \mathrm{t}}+\cdots+\beta_{\mathrm{n}, \mathrm{t}} \cdot \mathrm{R}_{\mathrm{n}, \mathrm{t}}+\varepsilon_{\mathrm{t}}, \quad \varepsilon_{\mathrm{t}} \sim \mathrm{N}\left(0, \sigma_{\varepsilon}^{2}\right) \\
\alpha_{\mathrm{t}+1}=\alpha_{\mathrm{t}}+\xi_{0, \mathrm{t}+1}, \quad \xi_{0, \mathrm{t}} \sim \mathrm{N}\left(0, \sigma_{\mathrm{i}, \xi}^{2}\right)
\end{gathered}
$$

$$
\beta_{\mathrm{i}, \mathrm{t}+1}=\phi_{\mathrm{i}} \cdot \beta_{\mathrm{i}, \mathrm{t}}+\xi_{\mathrm{i}, \mathrm{t}+1}
$$

for every $i=1,2, \ldots, n$ and $t=1,2, \ldots, m$. Above, $\mathrm{R}_{\mathrm{it}, \mathrm{t}}$ represents return of the fund or the indexes analyzed within period $t$ and $\alpha$ is the factor that represents the return that would not be correlated to the indexes and it would measure the manager's ability. In this study, such an a factor is modeled dynamically over time in the form of a random walk without drift. This choice is justified, according to Pizzinga, Vereda and Fernandes (2011), for three reasons: parsimony and simplicity, because it allows the possibility of key changes in the manager's selectivity, due to nonstationarity, and because it is not 'explosive.' The coefficients $\beta_{\mathrm{i}, \mathrm{t}}$ represent exposures to the indexes representing the $n$ asset classes at time $t$. According to equation 4, these exposures are modeled as first-order stationary autoregressive processes (the condition of $0<\Phi_{\mathrm{i}}<1$ was not restrictive throughout this research, because the coefficient values fell naturally in this interval).
As this article aims to analyze private pension funds and they have constraints regarding leverage, the portfolio constraint proposed by Sharpe (1992) has to be modeled, i.e. exposures should add up to $100 \%$. To do this, we just need to reparametrize the beta values. The exact procedure is detailed later.

As for the second constraint proposed by Sharpe (1992), i.e. non-negativity of exposures, according to Swinkels and Van Der Sluis (2002), it is generally not necessary. The authors argue that using these constraints may lead to inconsistent parameter estimates, when sold positions are allowed, indeed. In the case of open supplementary pension funds, according to Resolution no. 3,308, enacted on August 31, 2005, from the Central Bank of Brazil (BACEN), up to $10 \%$ of the assets may be invested in funds classified as exchange, in addition to $15 \%$ in multimarkets, which may have positions sold in any of the Brazilian market 
asset classes. Therefore, in this study no constraints are used concerning negative exposures.

\subsection{Kalman Filter}

As Lhabitant (2009) claims, if index exposures can vary over time, this variation must be explicitly modeled, as opposed to simply using movable windows, assuming they are constant along the window. In this case, the filter proposed by Kalman (1960) represents the most natural and indicated technique, since, for instance, it allows the most efficient use of available information. In fact, the filter proposed by Kalman (1960) seems to show empirical superiority over other methods. The only reason why it has not taken the place of traditional style analysis yet, is its complexity, both in terms of understanding and implementation (Lhabitant, 2009).

The filter proposed by Kalman (1960) is primarily a recursive prediction and correction algorithm. In a simplified way, the algorithm predicts a new state (containing all the information available to date) that starts from the previous state and it is corrected by a term proportional to the previous prediction error, in such a way that the current error is statistically minimized. Under the normality premise of the model's error terms, it becomes possible to calculate the prediction error's likelihood function, through which the model's unknown parameters are estimated.

If it is more adequate to use all the information available in the sample to estimate the state at a particular point in time, and not only the information available up to that point, the issue is named as smoothing problem. In other words, the difference is that the filter is conditional on information up to time $t$, therefore it is more suitable for prediction (i.e. out-of-sample), while smoothing is conditional with regard to the information contained in the whole sample, thus it is more adequate for descriptive purposes and ex-post (in-sample) analysis, which is the case of this study.

For the sake of brevity and space, equations from the filter proposed by Kalman (1960) will not be shown in this article, but they can be found in Durbin and Koopman (2012) with more information on derivations of the filter proposed by Kalman (1960).

\section{DATA AND METHODOLOGY}

In Brazil, selecting representative indexes for asset classes is often no easy task. Several authors who have already performed style analysis in Brazil have faced this issue, among them Linhares (2003), Marques (2006), Schutt and Caldeira (2014), and Varga and Valli (1998). As this study investigates exposures to asset classes of private pension funds, first it is worth checking which asset types the current legislation allows them to invest in. According to the Resolution no. 3,308/2005, from the BACEN, FIEs from the Brazilian open supplementary pension entities (EAPCs) may invest in the following segments: fixed income, variable income, real estate (directly or through real estate funds), and exchange (through foreign exchange funds).

Therefore, the selected indexes should seek to represent private pension fund exposures to these four market segments. After a search for the main indexes widely disclosed in the Brazilian market, it was decided to choose, for the fixed income market, the five indexes below:

- Anbima Market Index (IMA-B) 5 and IMA-B $5+$ : representing the assets linked to inflation (Brazilian National Consumer Price Index IPCA) in the short/medium and medium/long term;
- Fixed Income Market Index (IRF-M) 1 and IRF-M $1+$ : representing the assets tied to the short and medium/long-term pre-rate;

- Index consisting of the over interbank deposit (ID) rate (Brazilian Interbank Deposit Certificate - IDC): representing the exposure to ID funds.

For the variable income market, two indexes were initially chosen:

- BOVESPA Index (IBOVESPA): representing the highest and most traded stocks on the stock exchange;

- Small Cap Index (SMLL) from the São Paulo Stock Exchange, Commodities and Futures (BM\&FBOVESPA): representing the stocks from small companies traded on the stock exchange.

For the real estate market, we chose the Real Estate Investment Funds index (IFIX) from the BM\&FBOVESPA and, finally, for the exchange market, the Ptax rate. Data concerning all indexes were collected from the Bloomberg platform and data from the private pension funds analyzed were collected from the Quantum Axis platform.

The choice of funds to be analyzed was due to the 
relevance, in terms of equity managed by the institutions. Therefore, the top-five largest private pension institutions in Brazil, according to the FenaPrevi, are: Bradesco Vida e Previdência S.A., Brasilprev Seguros e Previdência S.A., Itaú Vida e Previdência S.A., Zurich Santander Brasil Seguros e Previdência S.A., and Caixa Vida e Previdência S.A. The institutions are henceforth named as Bradesco, Brasilprev, Itaú, Santander, and Caixa, respectively.

From each of these institutions, three funds were selected, representing three primary types: conservative, which only allows fixed income investments; moderate, which allows $15-30 \%$ (depending on the institution) of variable income; and aggressive, which can invest up to $40-49 \%$ (depending on the institution) in variable income. So, the choice of funds from each institution was based on equity under management and those chosen for analysis are displayed in Table 1. From here on, the funds are referenced by their corresponding numbers in Table 1.

In order to make the analysis period the same for all funds, since the start dates for disclosure of quotas are different, the date chosen to begin the analysis of all funds was January 2009. Another reason for choosing that date was the fact it was already within the post-2008 crisis period. The end of the analysis period was April 2015. All data were collected at daily intervals through the management fee recomposition, in order to obtain a series of returns with effects exclusively related to exposures to the asset classes under analysis.

Table 1 Funds chosen for analysis

\begin{tabular}{|c|c|}
\hline Institutions & Fund analyzed \\
\hline \multirow{3}{*}{ Bradesco } & Bradesco VGBL FIX FIC FI \\
\hline & Bradesco VGBL V15/30 FIC MM \\
\hline & Bradesco VGBL V40/30 FIC MM \\
\hline \multirow{3}{*}{ Brasilprev } & Brasilprev RT FIX FIC FI \\
\hline & Brasilprev Renda Total Composto 20 FIC MM \\
\hline & Brasilprev Renda Total Composto 49 FIC MM \\
\hline \multirow{3}{*}{ Itaú } & Itaú Flexprev FIC FI \\
\hline & Itaú Flexprev V20 FIC MM \\
\hline & Itaú Flexprev V40 FIC MM \\
\hline \multirow{3}{*}{ Santander } & Santander PREV FIX FIC FI PC \\
\hline & Santander PREV Moderado Superior FIC MM PC \\
\hline & Santander PREV Agressivo Superior FIC MM PC \\
\hline \multirow{3}{*}{ Caixa } & Caixa FIC FI Previdenciário \\
\hline & Caixa Renda Variável 0/15 FIC MM Previdenciário \\
\hline & Caixa renda variável 0/49 FIC MM Previdenciário \\
\hline
\end{tabular}

p.y. = per year; $P C=$ private credit; $M M=$ multimarket; $F I=$ fixed income.

Source: Prepared by the authors.

Regarding the methodology, the dynamic style analysis of the funds selected was divided into two parts. In the first and simpler analysis, the dynamic style analysis with movable windows is applied and the class indexes to be used in the later analysis, more complex and resorting to Kalman smoothing, are defined.

Starting with movable windows, an analysis is conducted for each pension fund, with all indexes representing asset classes previously selected. The size of the chosen window was six months: as the data used have a daily frequency, it was thought that six-month data might already be enough to have a reasonable sample size for analysis in each window. By means of this analysis, it is possible to verify, for each fund, which are the most relevant indexes.
For the next analysis step, only those indexes that exhibit significantly different non-zero exposure will be selected at some point in the analysis through movable windows. In this new step, analyzes will be done using Kalman smoothing in all selected pension funds. The choice of smoothing, rather than the filter proposed by Kalman (1960), was based on the argument by Swinkels and Van Der Sluis (2002), that smoothing is conditional on the whole sample, so it is more appropriate for descriptive purposes, which is precisely the objective of this study. The steps in this stage consist, for each fund, in:

1. Run the Kalman smoothing algorithm with all indexes selected from the previous step.

2. Check which index represented the smallest 
contribution to the explanation of fund's return and take it out from the set of indexes for that fund.

3. Re-run the Kalman smoothing algorithm with the new (smallest) set of indexes and check whether there were improved information criteria (Akaike information criterion - AIC),
Schwartz Bayesian information criterion (BIC), and mean squared error (MSE).

4. If there are improved indicators, go back to step 2 and go ahead; if there is no improvement, the previous model is selected.

\section{ANALYSIS AND RESULTS}

In this section, we present the results found according to the methodology proposed. In order not to affect the reading, the analysis is shown, when needed, only to the market leader institution (Bradesco) and full details of the analyses for the other funds are fully available with the authors.

\subsection{Preliminary Analysis Via Movable Windows}

The analysis begins with the full model (using all indexes representing asset classes) for all funds. As the IFIX only started to be disclosed since January 2011, a first analysis was conducted using that initial date for all funds. The IFIX did not prove to be significant in any analysis period for any of the funds, therefore it is the first index to be discarded (we worked with a 95\% confidence interval).

The analysis was conducted without IFIX and having as initial date January 2009 , as originally proposed. It was easy to see that no fund had a relevant exposure to the Ptax index. Consequently, it was decided to exclude the
Ptax index from the next analysis stage of all funds, as it did not contribute significantly to explain their returns. Conservative funds also did not show significant exposure to variable income, so the IBOVESPA and the SMLL were taken out of the next analysis stage for such funds. It is worth noticing that this result is totally in line with the fact that this is an exclusively fixed income fund.

Thus, Table 2 displays the summary of representative indexes of the asset classes, which, therefore, were not excluded during the analysis through movable windows, i.e. the indexes used in Kalman smoothing analysis.

\subsection{Kalman Smoothing Analysis}

In this step, a Kalman smoothing analysis is conducted in an iterative way, with each index being taken out from the model (initially according to Table 2) and comparing their indicators (AIC, BIC and MSE) to those of the previous model, in order to see if there was improvement. If so, the process goes ahead; otherwise, this model becomes the final model. 
Table 2 Indexes chosen to start Kalman smoothing analysis

\begin{tabular}{|c|c|c|c|c|c|c|c|c|c|}
\hline \multirow[t]{2}{*}{ Funds analyzed } & \multicolumn{9}{|c|}{ Chosen indexes } \\
\hline & IMA-B & IMA-B 5+ & IRF-M 1 & IRF-M 1+ & IDC & IBOVESPA & SMLL & Ptax & IFIX \\
\hline 1. Conservative Bradesco & $\checkmark$ & $\checkmark$ & $\checkmark$ & $\checkmark$ & $\checkmark$ & & & & \\
\hline 2. Moderate Bradesco & $\checkmark$ & $\checkmark$ & $\checkmark$ & $\checkmark$ & $\checkmark$ & $\checkmark$ & $\checkmark$ & & \\
\hline 3. Aggressive Bradesco & $\checkmark$ & $\checkmark$ & $\checkmark$ & $\checkmark$ & $\checkmark$ & $\checkmark$ & $\checkmark$ & & \\
\hline 4. Conservative Brasilprev & $\checkmark$ & $\checkmark$ & $\checkmark$ & $\checkmark$ & $\checkmark$ & & & & \\
\hline 5. Moderate Brasilprev & $\checkmark$ & $\checkmark$ & $\checkmark$ & $\checkmark$ & $\checkmark$ & $\checkmark$ & $\sqrt{ }$ & & \\
\hline 6. Aggressive Brasilprev & $\checkmark$ & $\checkmark$ & $\checkmark$ & $\checkmark$ & $\checkmark$ & $\checkmark$ & $\checkmark$ & & \\
\hline 7. Conservative Itaú & $\checkmark$ & $\checkmark$ & $\checkmark$ & $\checkmark$ & $\checkmark$ & & & & \\
\hline 8. Moderate Itaú & $\checkmark$ & $\checkmark$ & $\checkmark$ & $\checkmark$ & $\checkmark$ & $\checkmark$ & $\checkmark$ & & \\
\hline 9. Aggressive Itaú & $\checkmark$ & $\checkmark$ & $\checkmark$ & $\checkmark$ & $\checkmark$ & $\checkmark$ & $\checkmark$ & & \\
\hline 10. Conservative Santander & $\checkmark$ & $\checkmark$ & $\checkmark$ & $\checkmark$ & $\checkmark$ & & & & \\
\hline 11. Moderate Santander & $\checkmark$ & $\checkmark$ & $\checkmark$ & $\checkmark$ & $\checkmark$ & $\checkmark$ & $\checkmark$ & & \\
\hline 12. Aggressive Santander & $\checkmark$ & $\checkmark$ & $\checkmark$ & $\checkmark$ & $\checkmark$ & $\checkmark$ & $\checkmark$ & & \\
\hline 13. Conservative Caixa & $\checkmark$ & $\checkmark$ & $\checkmark$ & $\checkmark$ & $\checkmark$ & & & & \\
\hline 14. Moderate Caixa & $\checkmark$ & $\checkmark$ & $\checkmark$ & $\checkmark$ & $\checkmark$ & $\checkmark$ & $\checkmark$ & & \\
\hline 15. Aggressive Caixa & $\checkmark$ & $\checkmark$ & $\checkmark$ & $\checkmark$ & $\checkmark$ & $\checkmark$ & $\checkmark$ & & \\
\hline
\end{tabular}

Note: The full funds' names are available in Table 1.

$I D C=$ Brazilian Interbank Deposit Certificate; IBOVESPA = BOVESPA Index; IFIX = Real Estate Investment Funds index; IMA = Anbima Market Index; IRF = Fixed Income Market Index; SMLL = Small Cap Index.

Source: Prepared by the authors.

Through the results presented in Table 3 , we can see that all composite funds, i.e. those that also invest in variable income (moderate and aggressive), had high $\mathrm{R}^{2}$, varying from $96 \%$ to $99.6 \%$. This demonstrates that indexes from the final Kalman smoothing analysis model can explain much of these funds' returns. As pointed out by Sharpe (1992), the value of $\mathrm{R}^{2}$ can also be used as one of the means to measure the management activity level of a fund, while $1-\mathrm{R}^{2}$ can be assigned to manager selectivity. Therefore, $\mathrm{R}^{2}$ levels as high as those found in this study provide fairly strong indicators that these funds are passively managed.

Table 3 Result of iterative analysis via Kalman smoothing of the funds analyzed

\begin{tabular}{|c|c|c|c|c|c|c|c|c|}
\hline \multirow[t]{2}{*}{ Indicators } & \multicolumn{8}{|c|}{ Funds analyzed } \\
\hline & 1 & 2 & 3 & 4 & 5 & 6 & 7 & 8 \\
\hline IMA-B Index & $\checkmark$ & $\checkmark$ & $\checkmark$ & $\checkmark$ & - & - & $\checkmark$ & $\checkmark$ \\
\hline IMA-B 5+ Index & - & - & - & - & $\checkmark$ & $\checkmark$ & - & - \\
\hline IRF-M 1 Index & - & - & - & - & - & - & - & - \\
\hline IRF-M 1+ Index & - & - & - & - & - & - & - & \\
\hline IDC Index & $\checkmark$ & $\checkmark$ & $\checkmark$ & $\checkmark$ & $\checkmark$ & $\checkmark$ & $\checkmark$ & $\checkmark$ \\
\hline IBOVESPA & - & $\checkmark$ & $\checkmark$ & - & & $\checkmark$ & - & $\checkmark$ \\
\hline SMLL Index & - & - & - & - & - & - & - & - \\
\hline Ptax Index & - & - & - & - & - & - & - & - \\
\hline IFIX Index & - & - & - & - & - & - & - & - \\
\hline \multirow[t]{2}{*}{$\mathrm{R}^{2}$} & 0.855 & 0.988 & 0.990 & 0.852 & 0.994 & 0.995 & 0.110 & 0.990 \\
\hline & 9 & 10 & 11 & 12 & 13 & 14 & 15 & \\
\hline IMA-B Index & $\checkmark$ & $\checkmark$ & - & - & $\checkmark$ & $\checkmark$ & $\checkmark$ & \\
\hline IMA-B 5+ Index & - & - & & & - & - & - & \\
\hline IRF-M 1 Index & - & - & - & - & - & - & - & \\
\hline IRF-M 1+ Index & - & - & - & - & - & - & - & \\
\hline IDC Index & $\checkmark$ & $\checkmark$ & $\checkmark$ & $\checkmark$ & $\checkmark$ & $\checkmark$ & $\checkmark$ & \\
\hline IBOVESPA & $\checkmark$ & - & $\checkmark$ & $\checkmark$ & - & $\checkmark$ & $\checkmark$ & \\
\hline SMLL Index & - & - & - & - & - & - & - & \\
\hline Ptax Index & - & - & - & - & - & - & - & \\
\hline IFIX Index & - & - & - & - & - & - & - & \\
\hline $\mathrm{R}^{2}$ & 0.996 & 0.098 & 0.960 & 0.980 & 0.753 & 0.985 & 0.987 & \\
\hline
\end{tabular}

Note: the funds are referenced by numbers according to Table 1.

$I D C=$ Brazilian Interbank Deposit Certificate; IBOVESPA = BOVESPA Index; IFIX = Real Estate Investment Funds index; IMA = Anbima Market Index; IRF = Fixed Income Market Index; $S M L L=$ Small Cap Index.

Source: Prepared by the authors. 
Among conservative funds, in funds 1,4 , and 13 relatively high $\mathrm{R}^{2}$ were also found, about $75-85 \%$, indicating some passivity. However, in funds 7 and 10 it was not possible to find similar evidence. It is worth noticing that Sharpe (1992) himself comments on this issue: if on the one hand, high $\mathrm{R}^{2}$ may be indicative of passive management, on the other hand, low $\mathrm{R}^{2}$ does not necessarily indicate active management, since it can be a result of bad model specification or bad index choice representing the asset classes, for instance.

Indeed, in conservative funds, what might have occurred for a $\mathrm{R}^{2}$ at a lower level than the moderate or aggressive ones is that the indexes chosen to represent the fixed income market (IMA-B, IMA-B 5+, IRF-M 1, and IRF-M 1+) are, in fact, portfolios with securities having different maturities. So, if conservative funds have different durations (or they are concentrated in a few maturities), these portfolios can turn out to be bad proxies. Yet, then why did such indexes work well for moderate and aggressive funds? This is justified by the fact that, with variable-income funds, returns' variability increases sharply, and a generic fixed-income index may work relatively well when compared to its explanatory power of conservative fund, which has much less variability.
Generally, the indexes that were most relevant and, therefore, chosen for the final models were: IDC and a single index of inflation-linked government securities (IMA-B or IMA-B+) for conservative funds, added to the IBOVESPA for the moderate and aggressive. This composition makes sense when we think of the primary purpose of private pension funds, which is providing financial security for future retirement. Thus, a combination of fixed-rate securities and some protection against inflation, in order to obtain real profitability, seems to be the strategy chosen by the main conservative pension funds.

Another significant observation was that fixed rate securities' indexes did not seem relevant in any of the funds analyzed. A more active management of the fixedincome part of these funds should necessarily involve active management of fixed-rate securities, incorporating them into the portfolio when interest rates are high, for instance.

By way of illustration, figures 1,2, and 3 display the results of Kalman smoothing style analysis for the final models of funds 1, 2, and 3, respectively. The figures referring to funds from the other institutions showed a very similar pattern.

\section{Fund 1}
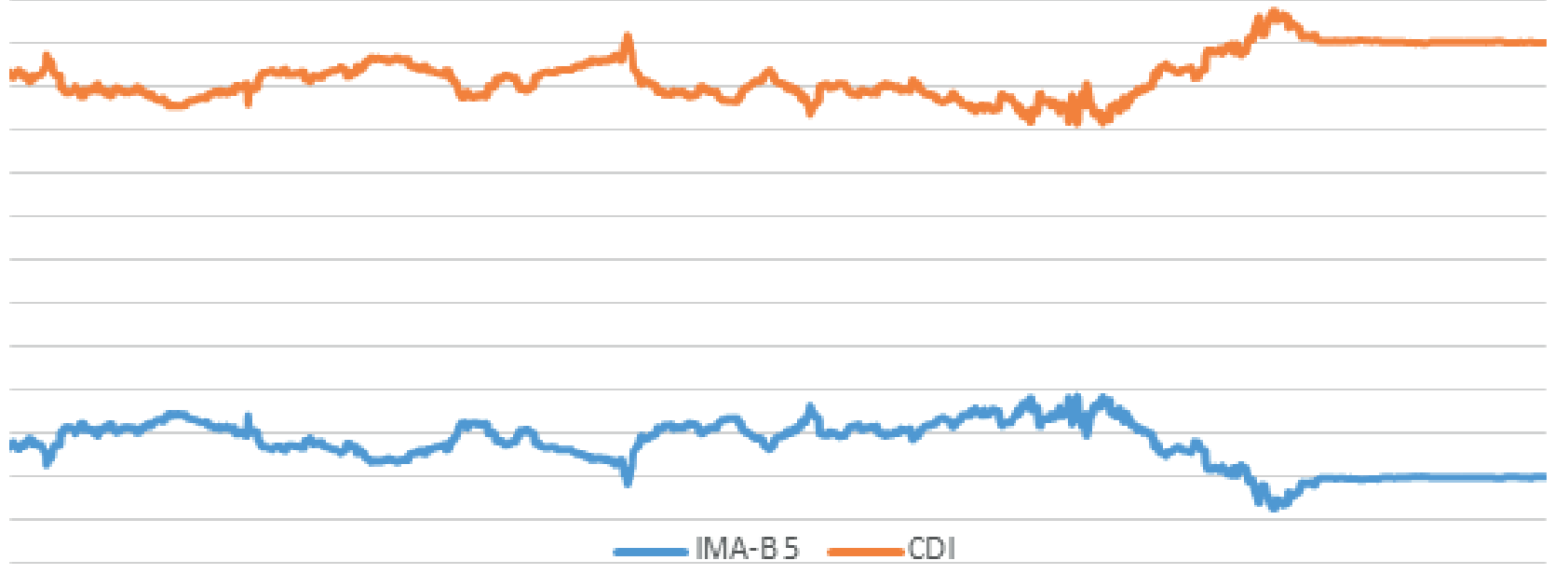

Figure 1 Final style analysis model via Kalman smoothing of fund 1. IDC = Brazilian Interbank Deposit Certificate; IMA = Anbima Market Index.

Source: Prepared by the authors. 


\section{Fund 2}
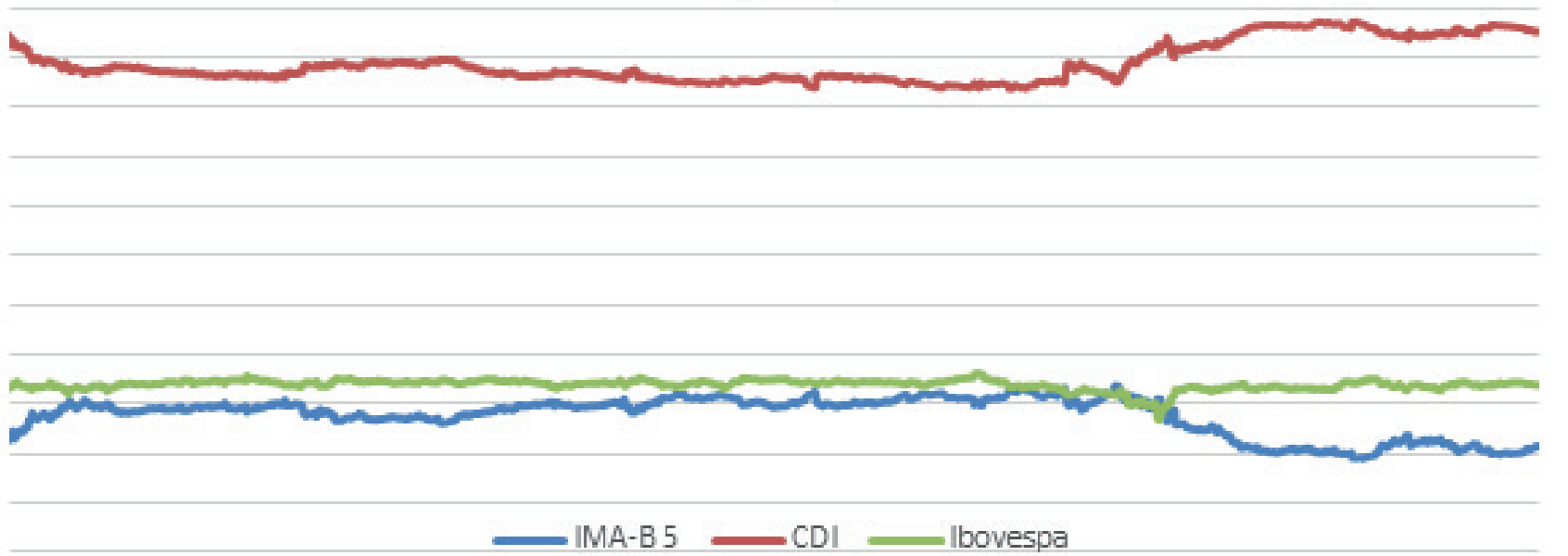

Figure 2 Final style analysis model via Kalman smoothing of fund 2.

$I D C=$ Brazilian Interbank Deposit Certificate; IMA = Anbima Market Index; IBOVESPA = BOVESPA Index.

Source: Prepared by the authors.

\section{Fund 3}

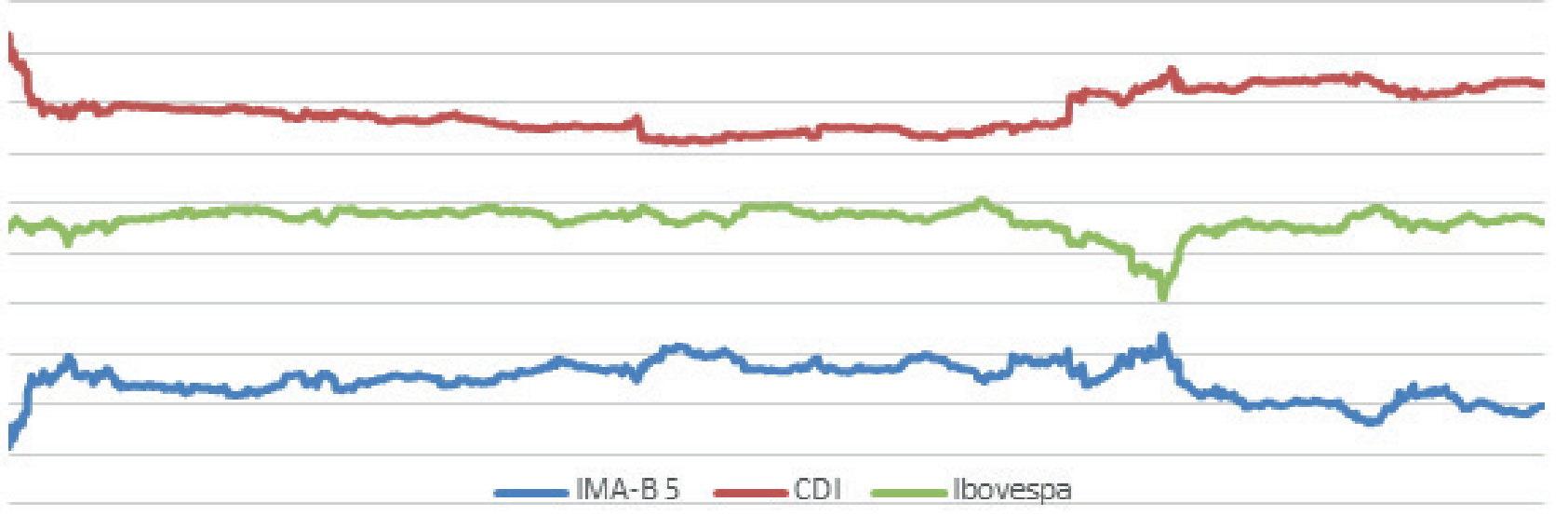

Figure 3 Final style analysis model via Kalman smoothing of fund 3.

$I D C=$ Brazilian Interbank Deposit Certificate; IMA = Anbima Market Index; IBOVESPA = BOVESPA Index.

Source: Prepared by the authors.

Interestingly, it is worth noticing in the figures that, in the second half of 2013 and the first half of 2014, filtered (and smoothed) positions in IDC increase to the detriment of the position in IPCA-linked securities (this effect is most pronounced in fund 1 , as it does not have a third position on the IBOVESPA). We conjecture that this movement occurred because the Brazilian economic situation at that time already showed signs of exhaustion, resulting in increased interest rates in the economy (to attract foreign investors). To get an idea, the IDC was $7.7 \%$ to $10.8 \%$ from June 2013 to July 2014, while the real interest rate (measured by the spread between IDC and IPCA) ranged from $1.4 \%$ to $4.1 \%$ within the same period. In this high interest rate scenario, the profitability of IDClinked securities (and consequently their percentage value in the portfolio) increases, but IPCA-linked securities tend to lose value due to the prefixed nature of the real interest rate embedded. 


\subsection{Additional Analyses}

As we saw in the previous section, moderate and aggressive funds from the private pension institutions analyzed seem to maintain stable positions in variable income, and these positions also do not show signs of being actively managed, with the IBOVESPA managing to capture much of these funds' return variance. These composite funds charge higher management fees than conservative funds from the same institutions, i.e. they invest only in fixed income. So, they were expected to be more active. However, what was observed in Kalman smoothing analyses was just the opposite: the $\mathrm{R}^{2}$ values found for composite funds were quite high, indicating greater passivity.

In Table 4, we can observe differences between the management fees charged by each institution for the funds analyzed and for an accumulated amount of $\mathrm{R} \$ 100,000$. These fees were collected through consumer services and information openly available on the institutions' websites in July 2015, in order to be representative of ordinary individuals seeking to apply their funds to these pension funds. Therefore, there may be changes in the case of exclusive products, special customers, or subsequent to the collection of such data. We observe there is a difference between the management fee charged by composite funds (with variable income investments) and by conservative funds, except for the Caixa's funds analyzed.

This situation of funds charging high management fees, theoretically in exchange for more active management, but delivering management that is actually passive or indexed, is not exclusive to Brazil. In Europe, this issue has been much discussed, both in the media and in the academia, even reaching some regulatory bodies.

In a recent Financial Times ("Closet tracker' funds more than doubled in the UK" - June 14, 2015) it is stated that the number of funds that may be regarded as closet trackers in the United Kingdom has doubled within the last 12 months. Also according to a recent study by the SCM Research (Smart Common Sense Modern, 2015), over $1 / 3$ of all funds in the United Kingdom are nothing more than expensive copies of index funds. All this demonstrates the scale and relevance of the issue to be faced and addressed by this study.

Table 4 Management fees charged by institutions for the funds analyzed by this study for individual clients with an accumulated amount about $R \$ 100$ thousand.

\begin{tabular}{|c|c|c|c|c|}
\hline \multirow[t]{2}{*}{ Institutions } & \multicolumn{2}{|c|}{$\begin{array}{l}\text { Conservative funds } \\
(\mathbf{1 0 0} \% \text { fixed income }) \\
(\%)\end{array}$} & \multicolumn{2}{|c|}{$\begin{array}{l}\text { Moderate and aggressive funds } \\
\text { (with variable income) } \\
(\%)\end{array}$} \\
\hline & PGBL & VGBL & PGBL & VGBL \\
\hline Bradesco & 1 & 1.5 & 2 & 2 \\
\hline Brasilprev & 1.5 & 1.5 & 2 & 2 \\
\hline Itaú & 1.75 & 1.75 & 2.5 & 2.5 \\
\hline Santander & 1.2 & 1.2 & 2 & 2 \\
\hline Caixa & 1.5 & 1.5 & 1.5 & 1.5 \\
\hline
\end{tabular}

$P G B L=$ Free Benefit Generating Plan; VGBL = Free Benefit Generating Life.

Source: Prepared by the authors.

Thus, in order to deepen the analysis of this problem in Brazil, in this section, we conducted the study with a focus on composite funds, since they are those that charge higher management fees and had the strongest evidence of passivity. In addition, the conservative fund itself may be used as a benchmark of fixed income investment, and in this way to verify if these composite funds can deliver higher performance to a simply passive portfolio consisting of a portion in the conservative fund from the institution added to a portion on the IBOVESPA.

The analysis was divided into two parts. The first focuses on verifying whether these composite funds deliver alpha, which might be a measure of the manager's skill. It proposes to measure how much performance this can deliver not correlated to the indexes chosen (e.g. related to timing and asset selectivity, i.e. manager skills). The second part focuses on the possibility of replicating the return of these composite funds, investing only in the conservative fund from the institution under analysis and on the IBOVESPA (via exchange traded funds ETFs), through a preconceived strategy. Thus, it might be possible to pay a lower management fee than when investing directly in the composite fund. 


\subsection{Do Composite Funds Deliver Alpha?}

In this subsection, we analyze if the composite funds studied are able to deliver alpha, i.e. a performance consistently above a passive portfolio consisting only of a portion in the conservative fund from the institution under analysis added to a portion on the IBOVESPA. To do this, a test was performed through a regression using only conservative fund's returns and the IBOVESPA without portfolio constraints, such as in a multifactor model. For this, the regression represented in equation 5 is used:

$$
R_{f, t}=\alpha+\beta_{c} R_{c, t}+\beta_{a} R_{a, t}+e_{t}
$$

in which $\mathrm{R}_{\mathrm{f}, \mathrm{t}}$ represents return of the composite fund at time $t, \mathrm{R}_{c, t}$ represents return of the conservative fund at time $t$, just as $\mathrm{R}_{\mathrm{a}, \mathrm{t}}$ represents IBOVESPA return at time $t$, $\beta_{c}$ and $\beta_{\mathrm{a}}$ represent exposures respectively to conservative fund and the IBOVESPA, $\alpha$ is independent return of $R_{c, t}$, and $\mathrm{R}_{\mathrm{a}, \mathrm{t}}$ and $\mathrm{e}_{\mathrm{t}}$ represent the error factor. Table 5 displays the results.

Table 5 Results of the test expressed by equation 5 (multifactor model conservative fund + BOVESPA Index)

\begin{tabular}{ccccccccccc}
\hline & \multicolumn{2}{c}{ Bradesco } & \multicolumn{2}{c}{ Brasilprev } & \multicolumn{3}{c}{ Itaú } & \multicolumn{2}{c}{ Santander } & \multicolumn{1}{c}{ Caixa } \\
\hline Fund & $\mathbf{2}$ & $\mathbf{3}$ & $\mathbf{5}$ & $\mathbf{6}$ & $\mathbf{8}$ & $\mathbf{9}$ & $\mathbf{1 1}$ & $\mathbf{1 2}$ & $\mathbf{1 4}$ & $\mathbf{1 5}$ \\
\hline Annualized $\alpha(\%)$ & 0.429 & 1.162 & -0.219 & -0.443 & -0.089 & 0.045 & -0.795 & -1.115 & -1.392 & -4.470 \\
\hline$P$ value of $\alpha$ & 0.2579 & 0.2507 & 0.3346 & 0.2852 & 0.7340 & 0.9241 & 0.1691 & 0.3683 & 0.0002 & 0.0001 \\
\hline
\end{tabular}

Source: Prepared by the authors.

As we can observe in Table 5, with the exception of funds 14 and $15, p$ values indicate that none of the funds had statistically significant alpha values at the $5 \%$ significance level (not even 10\%). For the specific cases of funds 14 and 15 , both alpha values were statistically significant, but negative. This suggests that composite funds are not able to generate alpha values related to the factors conservative fund + IBOVESPA or, when that is the case, they are negative.

However, this analysis does not consider the portfolio constraint, when the sum of weights in the conservative fund and in the IBOVESPA would have to equal $100 \%$. Then, we performed another test, in order to study the alpha value of each composite fund through a regression with the portfolio constraint. To do this, the regression represented in equation 6 is used.

$$
\mathrm{R}_{\mathrm{f}, \mathrm{t}}=\alpha+\left(1-\beta_{a}\right) \mathrm{R}_{\mathrm{c}, \mathrm{t}}+\beta_{a} \mathrm{R}_{\mathrm{a}, \mathrm{t}}+\mathrm{e}_{\mathrm{t}}
$$

In order to analyze the performance of the portfolio formed by means of this analysis, i.e. the portfolio formed by the conservative fund with constant weight $\left(1-\beta_{\mathrm{a}}\right)$ and by the IBOVESPA with constant weight $\beta$, we also calculated total return within the period and annualized volatility. The test results are shown in Table 6, where the portfolio built this way was named as benchmark and the composite fund analyzed was named simply as fund. 
Table 6 Results of the test expressed by equation 6 (conservative multifactor model + IBOVESPA, with portfolio constraint)

\begin{tabular}{|c|c|c|c|c|c|c|c|c|c|c|}
\hline \multirow[b]{2}{*}{ Fund } & \multicolumn{2}{|c|}{ Bradesco } & \multicolumn{2}{|c|}{ Brasilprev } & \multicolumn{2}{|c|}{ Itaú } & \multicolumn{2}{|c|}{ Santander } & \multicolumn{2}{|c|}{ Caixa } \\
\hline & 2 & 3 & 5 & 6 & 8 & 9 & 11 & 12 & 14 & 15 \\
\hline Annualized $\alpha(\%)$ & -0.250 & -0.678 & -0.045 & -0.220 & -0.195 & -0.240 & -0.590 & -1.105 & -0.279 & -0.398 \\
\hline$P$ value of $\alpha$ & 0.1069 & 0.0996 & 0.7841 & 0.4629 & 0.2315 & 0.4122 & 0.0887 & 0.1364 & 0.1262 & 0.5016 \\
\hline $\boldsymbol{\beta}_{\mathrm{a}}$ & 0.1359 & 0.3636 & 0.1818 & 0.3763 & 0.1941 & 0.3930 & 0.1576 & 0.4002 & 0.1225 & 0.4451 \\
\hline $\begin{array}{c}\text { Confidence interval } \\
(95 \%) \text { of } \boldsymbol{\beta}_{\mathbf{a}}( \pm)\end{array}$ & 0.0008 & 0.0021 & 0.0008 & 0.0015 & 0.0008 & 0.0015 & 0.0018 & 0.0038 & 0.0009 & 0.0031 \\
\hline $\mathrm{R}^{2}$ & 0.9861 & 0.9861 & 0.9916 & 0.9932 & 0.9924 & 0.9939 & 0.9504 & 0.9634 & 0.9767 & 0.9809 \\
\hline Fund's total return (\%) & 82.18 & 72.55 & 85.92 & 78.80 & 82.02 & 76.68 & 77.02 & 66.14 & 82.03 & 73.11 \\
\hline Benchmark's total return (\%) & 85.11 & 80.21 & 86.46 & 81.35 & 84.29 & 79.42 & 83.82 & 78.45 & 85.30 & 77.68 \\
\hline Fund's annualized volatility (\%) & 3.31 & 8.81 & 4.49 & 9.14 & 4.71 & 9.49 & 3.92 & 9.81 & 3.01 & 10.81 \\
\hline $\begin{array}{c}\text { Benchmark's annualized } \\
\text { volatility }(\%)\end{array}$ & 3.29 & 8.75 & 4.47 & 9.10 & 4.69 & 9.46 & 3.82 & 9.63 & 2.97 & 10.71 \\
\hline
\end{tabular}

Source: Prepared by the authors.

Table 6 shows that in none of the cases $p$ value was significant at a $5 \%$ significance level. When observing the values found for $\beta_{a}$, i.e. the IBOVESPA weights, we can see that their confidence intervals are very small when compared to the value found (all $p$ values virtually equal to zero, not shown in the table), suggesting there is not a rather active management of the portion of variable income portion in composite fund portfolios, since most of the time the IBOVESPA weights in the composite fund portfolio under analysis remain very close to the $\beta_{\mathrm{a}}$ values.

Another result that deserves attention is performance: all benchmarks built had higher returns as lower volatility. This is an indication that an investor may obtain similar or even better returns than those of composite funds, with simple strategies, such as that used.

\subsection{Is it Possible to Replicate the Performance of Composite Funds with a Lower Management Fee?}

In the previous subsection, we observe that all benchmarks built only by means of a fixed percentage in the conservative fund added to a fixed percentage on the IBOVESPA had better total returns and smaller volatilities than composite funds under analysis. However, this was an in-sample analysis, i.e. the whole sample was used to determine weights. Also, the socalled strategy would need daily rebalancing to keep up with the same ratio between conservative fund and the IBOVESPA, raising the strategy cost too much. This problem would occur because, since these two assets' daily returns are not necessarily equal, the portfolio would inevitably be unbalanced every day. Thus, the purpose of this subsection is developing an out-ofsample benchmark that can realistically be replicated at a low cost.

To achieve this goal, a passive benchmark was set up for each moderate/aggressive fund from the institutions consisting only of the conservative fund from each institution and the IBOVESPA. This benchmark was built as follows: each month $(m)$ the composite fund style, i.e. theoretical weights of each asset in the fund portfolio, is calculated through the simpler style analysis as proposed by Sharpe (1992), through multiple regression between returns, without intercept and having weight constraints adding up to $100 \%$. If the assets are weighed, a portfolio is used for the following month $(m+1)$. This procedure is repeated on a monthly basis, thus making rebalancing monthly and reducing transaction costs, besides constituting an out-of-sample analysis and perfectly replicable.

In order to assess the benchmark built against the fund studied, total return and annualized volatility were calculated again. For a statistical comparison between the return series of the passive benchmark calculated and the referent fund, Spearman's correlation and $p$ value of the Wilcoxon-Mann-Whitney test were used. The choice of this non-parametric test was found to be widely used in the literature when it comes to comparisons between funds, in addition to being considered more effective than $t$ when it cannot be said that data had normal distribution, which in fact occurred. In turn, Spearman's correlation is a non-parametric statistics that does not require assumptions about data distribution, besides allowing to detect non-linear relations. Table 7 displays the results. 
All Spearman's correlations in Table 7 are quite high, with the lowest of them still above $97.5 \%$, suggesting that the calculated benchmark's return series do not differ much from the original fund series (recalling that calculations were made with recomposed fund returns of the management fee). This suggestion is confirmed by results of the WilcoxonMann-Whitney test, which showed $p$ values all above
$94 \%$, i.e. far from rejecting the null hypothesis even at high significance levels (the null hypothesis of this test means that the two sample distributions are equal). When observing total return, we see that the benchmarks calculated gain in half of the cases analyzed, in addition to having, all of them, volatilities smaller than the funds.

Table 7 Indicators of benchmarks built (conservative + Bovespa Index) vs. funds analyzed

\begin{tabular}{|c|c|c|c|c|c|c|c|c|c|c|}
\hline \multirow[b]{2}{*}{ Fund } & \multicolumn{2}{|c|}{ Bradesco } & \multicolumn{2}{|c|}{ BrasilPrev } & \multicolumn{2}{|c|}{ Itaú } & \multicolumn{2}{|c|}{ Santander } & \multicolumn{2}{|c|}{ Caixa } \\
\hline & 2 & 3 & 5 & 6 & 8 & 9 & 11 & 12 & 14 & 15 \\
\hline Rho-Spearman & 0.9923 & 0.9922 & 0.9959 & 0.9962 & 0.9977 & 0.9977 & 0.9758 & 0.9813 & 0.9899 & 0.9896 \\
\hline Pval-Wilcoxon & 0.9461 & 0.9669 & 0.9954 & 0.9670 & 0.9618 & 0.9496 & 0.9687 & 0.9979 & 0.9936 & 0.9866 \\
\hline Fund's total return (\%) & 82.2 & 72.6 & 85.9 & 78.8 & 82.0 & 76.7 & 77.0 & 66.1 & 82.0 & 73.1 \\
\hline Benchmark's total return (\%) & 84.1 & 75.0 & 85.3 & 75.2 & 80.6 & 71.6 & 80.5 & 70.6 & 82.1 & 68.5 \\
\hline $\begin{array}{l}\text { Fund's annualized } \\
\text { volatility }(\%)\end{array}$ & 3.31 & 8.81 & 4.49 & 9.14 & 4.71 & 9.49 & 3.92 & 9.81 & 3.01 & 10.81 \\
\hline $\begin{array}{l}\text { Benchmark's annualized } \\
\text { volatility }(\%)\end{array}$ & 3.30 & 8.79 & 4.42 & 9.02 & 4.68 & 9.43 & 3.83 & 9.63 & 2.94 & 10.56 \\
\hline
\end{tabular}

Note: in bold, the comparatively higher results.

Source: Prepared by the authors.

Consequently, it is plausible to claim that it is possible to build a passive portfolio, formed only by a conservative fund from the institution and by the IBOVESPA, invested through an ETF (e.g. XBOV11 - Caixa ETF IBOVESPA Index Fund, which charges $0.5 \%$ p.y. as management fee), with similar style and returns with no statistically significant difference with regard to the moderate/ aggressive fund under analysis. It is worth noticing that the management fee would be lower than the conservative fund management fee due to lower ETF cost, therefore lower than the fee charged by the composite fund (moderate or aggressive).

As a robustness test, we performed the same analysis, but using the IBrX-100 index as a proxy for the Brazilian stock market returns. This index has one of the most liquid ETFs traded on the BM\&FBOVESPA, the BRAX11 (iShares IBrX - Brazil Index IBrX-100 Index Fund), with a management fee of only $0.2 \%$ p.y., less than the $0.5 \%$ p.y. of the IBOVESPA ETF. Also, the IBrX-100 index has historically more stocks than the IBOVESPA, providing greater diversification and more efficient performance. Hence, an additional test was performed to verify if it is possible to find results similar to those in Table 7 using the IBrX-100 as an explanatory factor of returns linked to the funds' variable income, instead of the IBOVESPA. The results are displayed in Table 8 , where the notation is the same as in Table 7.

Table 8 Indicators of benchmarks built (conservative $+I B R X-100)$ vs. funds analyzed

\begin{tabular}{|c|c|c|c|c|c|c|c|c|c|c|}
\hline \multirow[b]{2}{*}{ Fund } & \multicolumn{2}{|c|}{ Bradesco } & \multicolumn{2}{|c|}{ BrasilPrev } & \multicolumn{2}{|c|}{ Itaú } & \multicolumn{2}{|c|}{ Santander } & \multicolumn{2}{|c|}{ Caixa } \\
\hline & 2 & 3 & 5 & 6 & 8 & 9 & 11 & 12 & 14 & 15 \\
\hline Rho-Spearman & 0.9818 & 0.9817 & 0.9773 & 0.9765 & 0.9735 & 0.9729 & 0.9658 & 0.9725 & 0.9798 & 0.9795 \\
\hline Pval-Wilcoxon & 0.7041 & 0.7242 & 0.7612 & 0.7746 & 0.7607 & 0.7719 & 0.7293 & 0.7516 & 0.7398 & 0.7636 \\
\hline Fund's total return $(\%)$ & 82.2 & 72.6 & 85.9 & 78.8 & 82.0 & 76.7 & 77.0 & 66.1 & 82.0 & 73.1 \\
\hline $\begin{array}{l}\text { Benchmark's total } \\
\text { return }(\%)\end{array}$ & 88.0 & 85.2 & 90.5 & 85.9 & 86.8 & 83.8 & 84.8 & 80.9 & 86.1 & 81.5 \\
\hline $\begin{array}{c}\text { Fund's annualized } \\
\text { volatility }(\%)\end{array}$ & 3.31 & 8.81 & 4.49 & 9.14 & 4.71 & 9.49 & 3.92 & 9.81 & 3.01 & 10.81 \\
\hline $\begin{array}{c}\text { Benchmark's annualized } \\
\text { volatility }(\%)\end{array}$ & 3.27 & 8.71 & 4.35 & 8.89 & 4.60 & 9.28 & 3.79 & 9.54 & 2.92 & 10.48 \\
\hline
\end{tabular}

Note: in bold, the comparatively higher results.

Source: Prepared by the authors. 
The returns of benchmarks formed with the IBrX-100 also did not show statistically significant differences from their reference fund returns. However, all benchmarks showed higher cumulative returns and lower volatilities than reference funds, which is still a highly positive bias. These results corroborate the previous conclusion, i.e. it is possible to build portfolios with a style very similar to the moderated/ aggressive fund analyzed and having a performance at least equal (but with superiority bias), with a much lower management fee.

\section{CONCLUSION}

The main conclusion obtained in this study is that it is possible to build a passive portfolio, formed only by the conservative fund from the institutions analyzed and an ETF from a stock index (IBOVESPA or IBrX-100), with similar style and returns without statistically significant difference with regard to the respective moderate/ aggressive fund from the institutions under analysis, paying a lower management fee than those. If the ETF is based on the IBrX-100, the performance has an even higher bias, both in terms of higher average return and lower volatility.

Another significant result was the existence of strong passivity traces in the management of the funds analyzed, thus not justifying the high management fees charged, even when considering the Jensen's alpha values found. These traces are observed through the results of exposures found in the style analysis using the filter proposed by Kalman (1960), as well as by the analysis of determination coefficients $\left(\mathrm{R}^{2}\right)$. The situation is even more serious in moderate and aggressive funds from the institutions analyzed. These funds are precisely those that were expected to be more active, because they have a variable income portion. Nevertheless, they were those showing more passivity traces in management and those that, at the same time, charge the highest management fees.

Thus, a rather in-depth investigation by the Brazilian regulatory agencies regarding funds with closet trackers characteristics, especially social security, analyzed here, are recommended, just as in the case of the Sweden-led movement that has gained momentum in Europe. This is explained by the fact that, just as in Europe, evidence has been found of funds with high management fees for active management while they actually have passive performance management, merely replicating that of known market indexes. So, this study hopes to shed light and trigger the debate on this issue in Brazil.

A major consideration that should be made is that the results found herein are specific to the funds and the institutions analyzed. Although they are quite representative of their categories, since they are the largest open funds from the largest private pension institutions in Brazil, none of the results obtained may be indiscriminately generalized. Consequently, as a natural suggestion for further studies, it is recommended to deepen and extend the analysis developed herein. It may be extended to other funds or other private pension institutions, e.g. merely insurers (in contrast to large banking institutions' sectors) or even non-pension funds.

It is true that, for long-term investments, where higher management fees may be charged, income accumulation can be even more effective through pension funds, as they enjoy significant tax benefits. However, such an argument cannot be used to justify fees at the levels currently observed. The benefits of private pension funds are given by the government as a way to incentive retirement savings, and not by the institutions. Thus, by charging high management and loading fees, those who are taking advantage of much of the benefits offered by the government are private pension institutions, rather than individual savers. Is this the federal government's goal in providing such benefits? It seems to us this is not the case. 


\section{REFERENCES}

Amaral, T. R. S. (2013). Análise de performance de fundos de investimento em previdência. (Master's Dissertation). Universidade de São Paulo, São Paulo.

Banco Central do Brasil. (2005). Resolução n. 3.308, de 31 de agosto de 2005. Altera as normas que disciplinam a aplicação dos recursos das reservas, das provisões e dos fundos das sociedades seguradoras, das sociedades de capitalização e das entidades abertas de previdência complementar, bem como a aceitação dos ativos correspondentes como garantidores dos respectivos recursos, na forma da legislação e da regulamentação em vigor. Retrieved from http://www.bcb.gov.br/pre/ normativos/res/2005/pdf/res_3308_v1_o.pdf

Campani, C. H., \& Costa, T. (2016). Pensando na aposentadoria: previdência privada ou autoprevidência? Retrieved from http://www.coppead. ufrj.br/upload/publicacoes/428.pdf

Durbin, J., \& Koopman, S. J. (2012). Time series analysis by state space methods (2nd. ed.). Oxford: Oxford University Press.

Fung, W., \& Hsieh, D. A. (1997). Empirical characteristics of dynamic trading strategies: the case of hedge funds. Review of Financial Studies, 10(2), 275-302.

Gibson, R., \& Gyger, S. (2007). The style consistency of hedge funds. European Financial Management, 13(2), 287-308.

Harvey, A. C. (1990). Forecasting, structural time series models and the Kalman filter. Cambridge: Cambridge University Press.

Holmes, K. A., \& Faff, R. W. (2008). Style analysis, customized benchmarks, and managed funds: new evidence. Applied Financial Economics Letters, 4(4), 253-258.

Kalman, R. E. (1960). A new approach to linear filtering and prediction problems. Journal of Fluids Engineering, 82(1), 35-45.

Lhabitant, F. S. (2009). Hedge funds: quantitative insights. Chichester, NY: John Wiley \& Sons.

Linhares, R. A. (2003). Aplicação da análise de estilo baseada nos retornos para os fundos mútuos no mercado brasileiro (Master's Dissertation). Universidade Federal do Rio de Janeiro, Rio de Janeiro.

Markov, M., Mottl, V., \& Muchnik, I. (2004). Dynamic style analysis and applications. Retrieved from https:// papers.ssrn.com/sol3/papers.cfm?abstract_id=1971363
Marques, L. G. E. (2006). Eficiência de fundos de previdência: uma análise das classes de fundos disponíveis no mercado. Revista Brasileira de Risco e Seguro, 2(3), 68-84.

Marques, R., Pizzinga, A., \& Vereda, L. (2012). Restricted Kalman filter applied to dynamic style analysis of actuarial funds. Applied Stochastic Models in Business and Industry, 28(6), 558-570.

Nunes, L. L. (2015). Estilo e agrupamento de fundos: um estudo aplicado aos fundos multimercados brasileiros (Master's Dissertation). Universidade de São Paulo, São Paulo.

Pizzinga, A.,Vereda, L., \& Fernandes, C. (2011). A dynamic style analysis of exchange rate funds: the case of Brazil at the 2002 election. Advances and Applications in Statistical Sciences, 6(2), 111-135.

Pizzinga, A., Vereda, L., Azevedo, C. O., \& Fernandes, C. (2012). Análise dinâmica de estilo para fundos de investimentos brasileiros. Revista Brasileira de Risco e Seguro, 7(14), 1-34.

Schutt, I. G., \& Caldeira, J. F. (2014). Análise de estilo dinâmica de fundos multimercados: aplicação para o mercado brasileiro. In Anais do Encontro Nacional de Economia (p. 42). Natal, RN.

Sharpe, W. (1988). Determining a fund's effective asset mix. Investment Management Review, 2(6), 59-69.

Sharpe, W. (1992). Asset allocation: management style and performance measurement. Journal of Portfolio Management, 18(2), 7-19.

Smart Common Sense Modern. (2015). Closet indexation. The UK epidemic continues. Retrieved from http:// www.trueandfaircampaign.com/wp-content/ uploads/2015/02/SCM-direct-closet-indexationepidemic-continues-report-february-2015.pdf

Swinkels, L., \& Van Der Sluis, P. J. (2002). Returnbased style analysis with time-varying exposures. Retrieved from https://papers.ssrn.com/sol3/papers. cfm?abstract_id=291640

Varga, G., \& Valli, M. (1998). Análise de estilo de investimento baseada no retorno. Recuperado de http://www.fce.com.br/servicos/artigos.php\#

Yoshinaga, C. E., Castro Jr., F. H. F., Oda, A. L., \& Lucchesi, E. P. (2009). Análise de estilo em fundos multimercados com e sem alavancagem no Brasil. REGES: Revista Eletrônica de Gestão, 2(1), 9-21. 